\title{
Medical Education in Sudan: A Recommendation to Adopt Competency-based Medical Education Curricula for Improving Practices (SudaniMEDs)
}

\author{
Mohamed Hassan Taha
}

Corresponding Author: Mohamed Hassan Taha; email: mtaha@sharjah.ac.ae

Received 21 February 2019 Accepted 12 May 2019 Published 30 September 2019

Production and Hosting by Knowledge E

(c) Mohamed Hassan Taha. This article is distributed under the terms of the Creative Commons

Attribution License, which permits unrestricted use and redistribution provided that the original author and source are credited.

Editor-in-Chief:

Prof. Mohammad A. M. Ibnouf

\section{S OPEN ACCESS}

Sudan is a leading country in health professions education (HPE), a sector which started 100 years ago. The history of HPE in Sudan dates back to 1918 with the training of medical assistants, with a school for modern midwifery opening in 1921 [1]. The first college of medicine in Sudan-Kitchener School of Medicine (KSM) - was established in 1924 and is currently a part of the University of Khartoum [2]. About half-a-century later, two more medical schools-Juba University School in 1977 and Gezira University School in 1978_were established. In the 1990s, there was an enormous expansion in higher education, particularly in colleges of medicine, with more than 30 being inaugurated [3]. Currently, Sudan has more than 60 colleges of medicine.

Several problems facing newly established medical schools in Sudan have been identified in recent years: challenges in designing an appropriate curriculum, lack of essential educational resources crucial to run a school consistent with quality standards, extreme shortage of qualified medical faculty due to migration, and lack of appropriate clinical training facilities and teaching hospitals [2, 3]. Furthermore, there are concerns that the significant expansion of higher education in Sudan, along with unparalleled strategic planning for establishing these medical schools to ensure proper training of medical students and a clear national policy for ensuring the competency of graduates, might affect the quality of the services provided to patients $[3,4]$.

Several studies have suggested that the provision of high-quality and safe patient care can only be guaranteed if medical students receive proper clinical teaching [57]. Therefore, several medical schools worldwide are increasingly focused on improving clinical teaching, implementing competency-based medical education (CBME) [8]. CBME is an educational approach to guarantee that medical graduates develop the competencies required to fulfil patients' needs in society [9]. This means that teaching, 
learning, and assessment focus on the development of competencies and continues till the desired competency is achieved [10].

Most countries that have adopted CBME have used a national competency framework developed by local higher authorities. These frameworks do not necessarily aim at unifying the curricula of the medical schools in these countries, but instead ensure the minimal competencies required at the level of graduation for the safe provision of medical care.

Several competency frameworks have been developed and implemented worldwide: the CanMEDS initiative in Canada; the Accreditation Council of Graduate Medical Education of the United States of America; Tomorrow's Doctors: Recommendations on Undergraduate Medical Education in the United Kingdom; the Scottish Doctor Competency Framework; Good Medical Practice; the Australian curriculum framework for junior doctors; the 2009 framework for undergraduate medical education in the Netherlands; Swedish medical education standards; the Brown University Nine Abilities, Medical School Objectives Project by AAMC; Global Minimal Essential Requirements; the European Medical Tuning Project; Dundee 12 outcomes; and the International Medical College Outcomes Malaysia [11-16]. Figures 1 and 2 show examples of these competency frameworks, focusing on the main themes around which the core competencies have been developed.

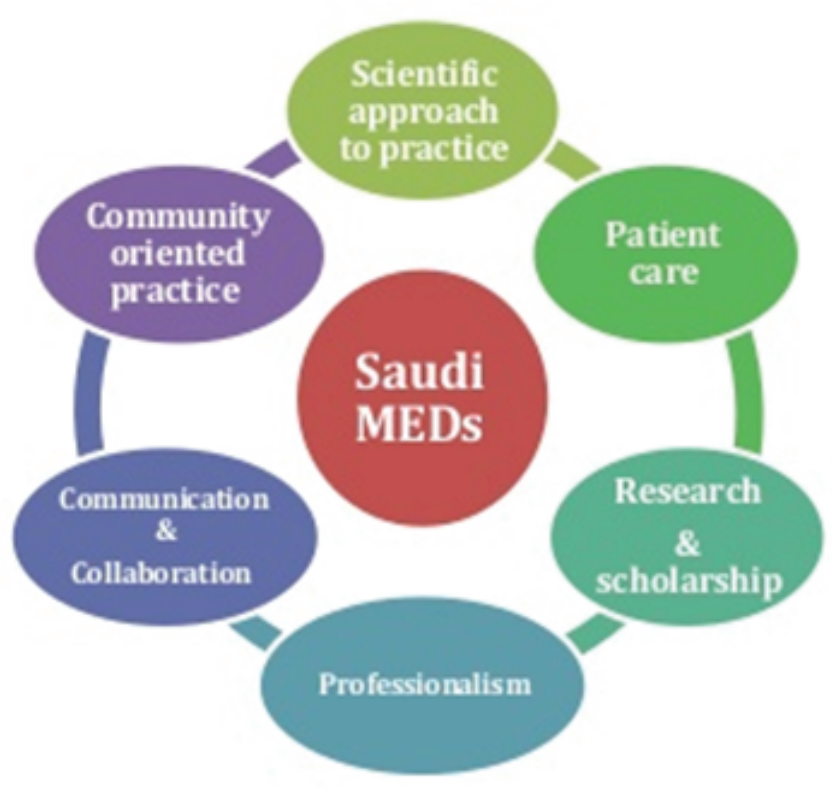

\section{The six themes of SaudiMED}

Figure 1: Example of National Competency Framework in the region (SaudiMEDs) [18]. 


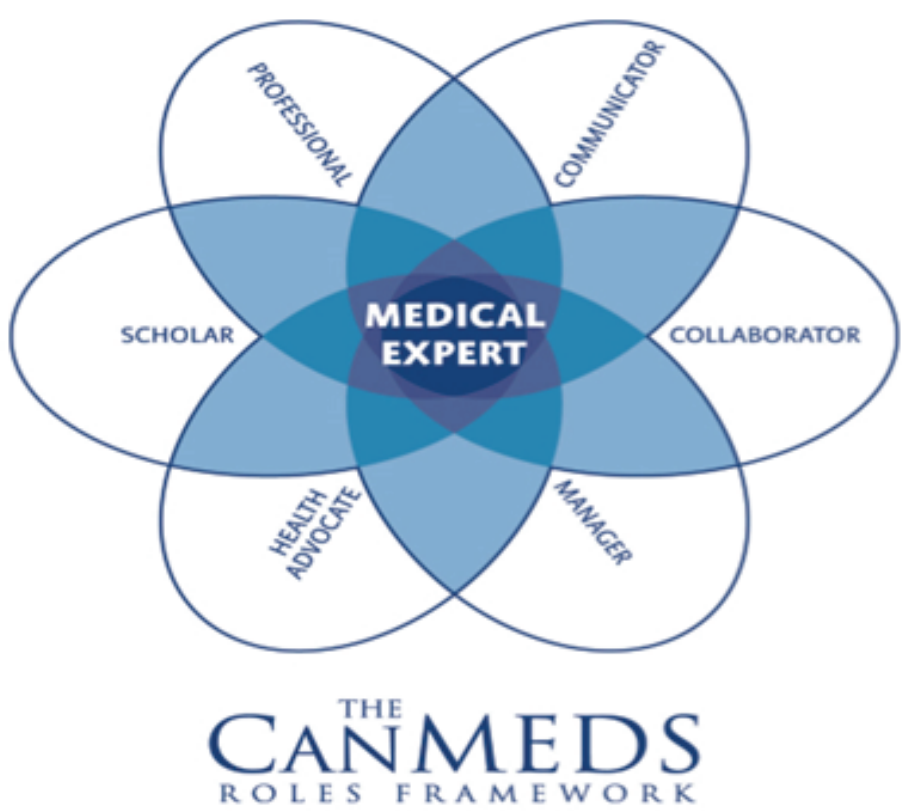

Figure 2: Example of National Competency Framework in Canada (CanMEDs) [19].

\section{Roadmap for the Development of the National Compe- tency Framework (Sudanese Medical Education Direc- tives SudaniMEDs)}

Similar to most international frameworks, the following approach is suggested:

1. Review of previous work.

2. Running of many workshops and virtual meetings to develop the first draft of the framework.

3. Agreement of the major domains, sub-domains, and competencies/learning outcomes following these consultative workshops.

4. Involvement of the stakeholders, which could be achieved by the use of the Delphi technique [17].

5. Involvement of all Sudanese medical schools and national medical education experts.

6. Review of the finalized framework by international experts of medical education who participated in developing national and international CBME frameworks and are involved in accreditation of medical schools worldwide.

These steps are important, but the most important points that need to be considered in experts' views and recommendation should have been taken into consideration in 
the final draft of the Sudanese national competency framework; Sudanese Medical Education Directives (SudaniMEDs).

\section{Elements of the Suggested Framework}

This framework might be developed at different levels, including (a) core competencies for undergraduate medical curricula for Sudanese doctors, (b) enabling competencies that should be useful as guidance for learning outcomes in the medical curriculum, (c) clinical presentations that clinical training needs to emphasize, and (d) clinical skills and procedures needed to be mastered before graduation.

\section{The Importance of SudaniMEDs (Suggested Framework)}

This framework should be used as a guiding principle for curriculum design and development for all medical schools. The core competencies of the graduates and their characteristics could be shaped from the core competencies for this framework. The course learning outcomes could also be extracted from this framework. Moreover, all clinical presentations and skills that should be covered in undergraduate medical schools in Sudan could be extracted from this framework.

\section{Who Should Collaborate to Develop this Framework?}

Several higher authorities and governing bodies could participate in the development of this national framework and transformation into CBME, such as the Association of Deans of Medical Schools, the Sudanese Association of Medical Education, medical education development centers in medical schools, the Sudan Medical Council, the Sudan Medical Specialization Board, and national and international experts in medical education.

\section{References}

[1] Haseeb, M. A. (1967). Medical education in the Sudan. Academic Medicine, vol. 42, no. 7, pp. 666-672.

[2] Fahal, A. H. (2007). Medical education in the Sudan: its strengths and weaknesses. Medical Teacher, vol. 29, no. 9, pp. 910-914. 
[3] Ahmed, A. A. (2012). Medical education in Sudan: emerging issues and acute needs. Sudanese Journal of Public Health, vol. 7, no. 2, pp. 56-64.

[4] Ahmed, Y., Taha, M. H., Alneel, S., et al. (2018). Evaluation of the learning environment and the perceived weakness of the curriculum: student perspective. International Journal of Research in Medical Sciences, vol. 7, no. 1, p. 165.

[5] Tolsgaard, M. G. (2013). Clinical skills training in undergraduate medical education using a student-centered approach. Danish Medical Journal, vol. 60, no. 8, p. 14.

[6] Leach, D. C. and Philibert, I. (2006). High-quality learning for high-quality health care: getting it right. JAMA, vol. 296, no. 9, pp. 1132-1134.

[7] Taha, M. H., Ahmed, Y., Abdalla, M.E., et al. (2019). Exploring factors affecting the quality of postgraduate medical education in Sudan: residents perspective. International Journal of Research in Medical Sciences, vol. 6, no. 2, pp. 1-9.

[8] Harden, R. M. (2006). Trends and the future of postgraduate medical education. Emergency Medicine Journal, vol. 23, no. 10, pp. 798-802. Retrieved from: http: //emj.bmj.com/cgi/doi/10.1136/emj.2005.033738

[9] Frank, J. R., Snell, L. S., Ten, C. O., et al. (2010). Competency-based medical education: theory to practice. Medical Teacher, vol. 32, no. 8, pp. 638-645.

[10] lobst, W. F., Sherbino, J., Cate, O. T., et al. (2010). Competency-based medical education in postgraduate medical education. Medical Teacher, vol. 34, no. 8, pp. 651-656.

[11] Rose, S. H. and Long, T. R. (2010). Accreditation council for graduate medical education (ACGME) annual anesthesiology residency and fellowship program review: a "report card" model for continuous improvement. BMC Medical Education, vol. 10, no. 1, p. 13.

[12] Bandiera, G., Sherbino, J., and Frank, J. R. (2006). The CanMEDS assessment tools handbook: an introductory guide to assessment methods for the CanMEDS competencies. Royal College of Physicians and Surgeons of Canada.

[13] Committee GMCE. (1993). Tomorrow's doctors: recommendations on undergraduate medical education. General Medical Council London.

[14] Ross, M. T., Macrae, C., Scott, J., et al. (2014). Core competencies in teaching and training for doctors in Scotland: a review of the literature and stakeholder survey. Medical Teacher, vol. 36, no. 6, pp. 527-538.

[15] Laan, R. F. J. M., Leunissen, R. R. M., and Van Herwaarden, C. L. A. (2010). The 2009 framework for undergraduate medical education in the Netherlands. Tijdschr voor Med Onderwijs, vol. 29, no. 1, pp. 10-15. 
[16] Ahmed, Y., Taha, M. H., Al-Neel, S., et al. (2018). Students' perception of the learning environment and its relation to their study year and performance in Sudan. International Journal of Medical Education, vol. 9, pp. 145-150.

[17] Hsu, C.-C. and Sandford, B. A. (2007). The Delphi technique: making sense of consensus. Practical Assessment, Research and Evaluation, vol. 12, no. 10, pp. 1-8.

[18] Zaini, R. G., Bin Abdulrahman, K. A., Al-Khotani, A. A., et al. (2011). Saudi Meds: a competence specification for Saudi medical graduates. Medical Teacher, vol. 33, no. 7, pp. 582-584.

[19] Frank, J. R., Snell, L., and Sherbino, J. (2014). The draft CanMEDS 2015 physician competency framework-series IV. Ottawa R Coll Physicians Surg Canada. 